2014-01-01

Finite element modelling of residual stresses in shot-peened steam turbine blades

\title{
Newby, M
}

http://hdl.handle.net/10026.1/3823

\section{$10.1111 /$ ffe. 12165}

Fatigue and Fracture of Engineering Materials and Structures

All content in PEARL is protected by copyright law. Author manuscripts are made available in accordance with publisher policies. Please cite only the published version using the details provided on the item record or document. In the absence of an open licence (e.g. Creative Commons), permissions for further reuse of content should be sought from the publisher or author. 


FiA $M S=$

\section{FE Modelling of Residual Stresses in Shot-Peened Steam Turbine Blades}

\begin{tabular}{|r|l|}
\hline Journal: & Fatigue \& Fracture of Engineering Materials \& Structures \\
\hline Manuscript ID: & FFEMS-5475 \\
\hline Manuscript Type: & Original Contribution \\
\hline Date Submitted by the Author: & 05-Nov-2013 \\
\hline Kemplete List of Authors: & $\begin{array}{l}\text { James, Neil; University of Plymouth, Marine Science \& Engineering } \\
\text { Newby, Mark; ESKOM, } \\
\text { Hattingh, Danie; NMMU, Mechanical Engineering }\end{array}$ \\
\hline \multicolumn{2}{|c|}{$\begin{array}{l}\text { Shot-peening, Residual stress, Turbine blade component, Finite element } \\
\text { modelling }\end{array}$} \\
\hline
\end{tabular}

SCHOLARONE $^{\mathrm{m}}$
Manuscripts 


\title{
FE Modelling of Residual Stresses in Shot-Peened
}

\section{Steam Turbine Blades}

\author{
$\mathrm{M} \mathrm{Newby}^{1,2^{*}}, \mathrm{MN}$ James $^{2,3}$ and DG Hattingh ${ }^{3}$
}

\begin{abstract}
The attachment region in steam turbine blades is critical to structural integrity and hence surface treatment by shot peening or roller burnishing is commonly used to induce compressive residual stresses in the fir-tree region of the blade. In particular, the last stage blades on the low pressure (LP) rotors present the highest risk in terms of catastrophic failure due to their size and operating conditions. These blades have a mass of some $24 \mathrm{~kg}$ and operate in a wet steam environment at approximately $60^{\circ} \mathrm{C}$ while rotating at $3,000 \mathrm{rpm}$; potential failure modes include high and low cycle fatigue, stress corrosion cracking and corrosion fatigue. This paper reports the development of, and results obtained from, an elastic-perfectly plastic (EPP) finite element (FE) model of the residual stresses in the attachment region of a last stage blade and the influence on these compressive stresses of fatigue cycling. The model uses thermal quenching to simulate the residual stress profile obtained in the fir-tree serrations after shot peening. Results were validated via extensive synchrotron and laboratory x-ray diffraction measurements of the residual stress in shot peened specimens.
\end{abstract}

Keywords: FE modelling; residual stresses; steam turbine blades; fatigue; shot-peening

\footnotetext{
1 Eskom Holdings SOC Ltd Lower Germiston Road, Rosherville, Johannesburg, South Africa mark.newby@eskom.co.za

$2 \quad$ School of Marine Science \& Engineering, University of Plymouth, Drake Circus, Plymouth, UK mjames@plymouth.ac.uk

3 Department of Mechanical Engineering, Nelson Mandela Metropolitan University, Port Elizabeth, South Africa, danie.hattingh@nmmu.ac.za
} 


\section{Introduction}

In a typical $600 \mathrm{MW}$ steam turbine generator set used by the South African power utility Eskom, the main steam pressure and temperature at the entry to the turbine are approximately $16.4 \mathrm{MPa}$ and $535^{\circ} \mathrm{C}$. This steam passes through a turbine train comprised of a high pressure (HP) stage, an intermediate pressure (IP) stage and then two low pressure (LP) stages. The energy extracted from the steam causes the turbine train to rotate and drive the two-pole electrical generator. The South African electrical grid operates at $50 \mathrm{~Hz}$, so the shaft speed of the turbo generator is $3,000 \mathrm{rpm}$. A typical steam flow path schematic is shown in Figure 1. The percentage power contribution to the $600 \mathrm{MW}$ output from each stage in the turbine is; HP casing $28 \%$, IP casing $39 \%$ and LP casings $17 \%$ each. Maximum steam turbine entry temperatures vary from $540^{\circ} \mathrm{C}$ in the HP and IP casings to $250^{\circ} \mathrm{C}$ in the LP casings, as shown in Figure 1.

Turbine blade design has to consider and find a design compromise between various material and operational variables. These include efficiency of turbine output, mechanical strength, the dynamic blade response to vibrational excitation, resistance to environmental effects such as corrosion, as well as the fatigue and thermal characteristics of the material. Fatigue failure is particularly important, as the sources of loading on steam turbine blades are varied and include normal operation, excitation of natural frequencies during transient events such as start-ups or during normal operation, and overloads experienced during proof testing. Reference 1 reviews major steam turbine problems related to their corrosive operating environment, e.g. stress corrosion cracking, corrosion fatigue and pitting, and discusses their root causes and solutions. The critical position for initiation of cracks on turbine blades is in the top serration of the fir-tree root attachment and shot-peening or roller burnishing are therefore widely used on this blade region to enhance their resistance to crack initiation by fatigue or stress corrosion cracking. 
In 2003, cracking in a last stage blade on an LP rotor led to the catastrophic failure of a turbo-generator set on a South African power station causing severe damage and costing in excess of $€ 100 M$ to repair. The failed fir-tree root is shown in the inset image in Figure 2. Following this failure, an internal Eskom report raised concerns over the effectiveness of the shot peening process in delivering fatigue life improvements [2]. These concerns focused on two main issues; firstly, the success in achieving a peening coverage and hence residual stress profile over the complex geometry of the fir-tree serrations and, secondly, any reduction in residual stress that may occur during operation. In particular, overspeed tests to $3,300 \mathrm{rpm}$ are performed periodically during turbine operation, usually following maintenance work that may have affected the balance of the rotor, whilst rotor speeds of 3,600 rpm can be experienced during statutory in-situ testing of the turbine overspeed protection systems. These speeds induce stresses in the attachment region that may exceed the proof strength of the blade alloy.

A programme of work was therefore initiated to accurately measure the residual stresses in the fir-tree attachment region as a function of shot peening coverage, using laboratory and synchrotron X-ray facilities, and to assess the decay in the surface residual stress arising from the application of cyclic stresses equivalent to operation at speeds of 3,300 and 3,600 rpm. Alongside this, a finite element model of the blade root region was developed to predict the shot peening residual stresses onto which the operational stresses could be superimposed and hence any reduction in residual stress arising from local plasticity could be calculated. This model was validated using the experimentally measured residual stress data and therefore the influence of fatigue loading can be found via this model for any given level of shot peening coverage.

A previous paper by the authors has presented some of the results of the residual stress measurements made on the blades and blade material [3], and the current paper considers the sources of turbine blade loading, briefly reviews the residual stress data obtained from 
the various experimental X-ray techniques, presents the effect of fatigue cycling on the peak residual stress values, and focusses on the development of, and output from, the FE model.

\section{Turbine Blade Dynamics}

The typical design life of a low pressure steam turbine rotor installed in the 1980's was 100,000 hours, with current designs being rated at 200,000 hours [4,5]. Many turbines are therefore being operated beyond their design life and accurate knowledge of changes in residual stresses induced in the fir-tree attachment region during operation is clearly of significant interest. According to McCloskey et al $[6,7]$ "fatigue in LP turbine blades is one of the most common underlying causes of steam turbine failures". The possibility of fatigue or stress corrosion failures is exacerbated by the unfavourable operational environment.

Normal operational stresses can include $[4,6,7]$ :

- Centrifugal stresses that result in tensile, bending and torsional effects

- A steady state steam bending stress from the passage of steam through the blades

- Stresses caused by stiffening attachments such as blade shrouds, lashing wire or wing bands.

- Dynamic stresses due to vibrational effects, particularly if natural frequencies are excited and resonance occurs, as discussed further below

- Thermally-induced stresses during transients such as start-up and shut-down conditions

- Effects of stress concentrations such as blade root attachments, which could be firtree dovetails or pinned forks, as well as any other sharp radius

Of these stress categories, probably the most difficult to quantify is the case where stresses are caused by vibration. Vibration-induced stresses in turbine blades have numerous sources, which include [7]: 
- Non-uniform pressures along the steam flow path due to velocity or angle changes in the steam flow arising, for example, from such factors as partial steam admission, bending of steam flow at inlet/outlet, leakage at diaphragm half joints, damaged diaphragm blades, stay-bars, and aerodynamic effects such as nozzle wakes.

- Unsteady flow in stationary flow passages due to factors such as choked flow and flow separation

- Stall and flutter across the blades which causes cavitation

- Disk-induced vibration resulting in activation of disk nodal resonance modes

- Moisture-induced vibration, particularly on the last stage blades where the steam has the highest moisture content

Non-uniform pressures and choked flows generally result in a flow discontinuity which causes a pressure pulse to be applied to the blades once every revolution. This can result in excitation of blade natural frequencies with detrimental consequences for the blade life. The resulting dynamic stresses depend on the natural frequency and mode shape of the blade, the frequency and shape of the exciting force, and the energy dissipating mechanism present in the system, which is included as damping. The Electric Power research Institute (EPRI) guideline on steam path turbine damage [7] provides an overview summary of blade stresses and their potential contribution to fatigue crack initiation and growth.

The deformed blade shapes that occur in the first three natural frequency modes are shown in Figure 3. The wire frame FE model shows the undeformed shape of the blade. The potential for resonance is normally evaluated through the use of a Campbell diagram. The Campbell diagram is widely used in rotordynamics to determine intersections between rotor natural frequencies and rotational speed, also expressed as a frequency. It plots engine order lines, which represent excitation under periodic forces and which are obtained as integer multiples of the shaft speed in Herz, against the shaft speed in rpm. The turbine disk and blade natural frequencies, obtained either from measurement or analysis, are then 
superimposed on this diagram to determine potential resonant conditions, which correspond with the intersection between engine order and natural frequency lines.

In the case of the blade failure experienced by Eskom in 2003, failure analysis and associated FE modelling work indicated that the failure involved stress corrosion cracking and fatigue at the first serration in the fir-tree region and that the first three natural frequency modes had contributed to the stresses in the blade. Figure 4 illustrates this for a typical turbine where the shaft is rotating at the full speed of $3,000 \mathrm{rpm}$ and the $4^{\text {th }}$ engine order line coincides with the first natural frequency line for the blade. It is therefore clear that the residual stresses induced by shot peening, their uniformity in the critical fir-tree region and their relaxation under service loading are important to improved prediction of the fatigue performance of steam turbine blades.

\section{Residual Stress Measurements}

Previous work by James et al [2] provided full experimental details and reported the results from a comprehensive program of synchrotron X-ray diffraction (SXRD) measurements on shot peened specimens cut from an ex-service blade (a 12CrNiMo martensitic steel to DIN 1.4939 with the trade name Jethete M152). This steel has a measured (average of 3 specimens) $0.2 \%$ proof stress of $868 \mathrm{MPa}$, tensile strength of $1048 \mathrm{MPa}$, elastic modulus of 204.2 GPa and a Poisson's ratio of 0.3. Residual stress measurements were made on twelve flat specimens intended to examine the effect of different shot peening coverage levels, the coverage at which a consistent level of residual stress was attained, and the reduction in residual stress after fatigue cycling. Alongside these tests the uniformity of residual stress achieved around the root of the first fir-tree serration was checked in three firtree samples. In this respect, laboratory XRD measurements were made at ten points around the top serration of one of the fir-tree samples using a Proto iXRD instrument. This work indicated the existence a uniform residual stress profile in the root region, with a mean residual stress value of $-479.3 \mathrm{MPa}$ and a standard deviation of $21.1 \mathrm{MPa}$. 
Shot peening of the fir-tree specimens was performed using the standard Eskom procedure (200\% coverage) that conforms to SAE AMS-S-13165 and calls for six nozzles to be used during the peening process [8]. The blade is mounted on a turntable and is then rotated whilst the shot peening nozzles move up and down.

For the flat specimens uniform coverage could be achieved using two nozzles and four groups of three specimens were prepared with four different coverage levels between $75 \%$ and $200 \%$. This part of the work was intended to ascertain the level of coverage required to achieve a steady-state value of residual stress and the surface values achieved were measured using laboratory X-ray equipment (a PANalytical X'pert Pro instrument) prior to taking the specimens to the European Synchrotron Radiation Facility (ESRF) for SXRD residual stress measurements. As shown in Table 1, the shot peening system produced a consistent level of surface residual stress on the flat specimens at all the coverage levels used in this work, with a mean value of $566 \mathrm{MPa}$ and a standard deviation of $16.4 \mathrm{MPa}$. This observation is supported both by the work by Prevéy and Cammett on 4340 steel plate [9] who found that no systematic variation occurred in the residual stress profile once the coverage value exceeded $20 \%$, and by the results of the SXRD work.

Synchrotron X-ray diffraction (SXRD) measurements were made at the ESRF using beam line ID31, in experiment MA-326 and beamline ID15A in experiment ME-1165. The SXRD data provided residual stresses profiles through the complete $5 \mathrm{~mm}$ cross-section of the flat samples at high spatial resolution, and the ESRF has the additional capability of performing in-situ fatiguing on the beamline. In experiment MA-326 residual stresses were measured in the as-peened condition for all flat and fir-tree specimens. In addition, tensile fatigue loading was applied to specimens using a $50 \mathrm{kN}$ servo-hydraulic testing machine in an on-site laboratory, as detailed in Table 1. The chosen tensile stress level of $868 \pm 20 \mathrm{MPa}$ applied for 10,000 cycles, was intended to simulate overspeed tests at $3,300 \mathrm{rpm}$ and led to a 
substantial reduction in residual stress in the specimens due to plastic deformation $(0.2 \%$ proof strength of the blade alloy is $868 \mathrm{MPa}$ ). The effect of fatigue cycling was therefore reexamined using more progressive in-situ fatigue loading on beamline ID15A (experiment ME1165) using the same $50 \mathrm{kN}$ servohydraulic testing machine. Table 2 gives details of the load sequence applied to specimen 6 with 100\% coverage.

Figure 5 gives the SXRD residual stress data measured over the first $0.8 \mathrm{~mm}$ below the shot peened surface. The results show the typical profiles expected from shot-peening with a maximum compressive stress occurring just below the blade surface, changing towards tension over a few hundred microns. The shape of the gauge volume used in synchrotron diffraction (an elongated diamond) makes it difficult to measure the residual stress precisely at the surface of a specimen. However, an average value of $571 \mathrm{MPa}$ was recorded for the four coverage conditions (8 specimens) which compares well with the measured laboratory X-ray surface average of $566 \mathrm{MPa}$ from 12 specimens.

The first point that was considered during the programme of in-situ loading was whether any stress relaxation would occur at the stress corresponding with the limit of elastic proportionality in the tensile stress-strain curve (600 MPa). Applying in-situ fatigue loading with a mean stress of $600 \mathrm{MPa}$ and stress amplitude of $\pm 20 \mathrm{MPa}$, did not lead to any reduction in residual stress. However, applying stress cycles with a mean stress of $848 \mathrm{MPa}$ and stress amplitude of $\pm 20 \mathrm{MPa}$, which corresponds to the overspeed test situation where the blade may reach its $0.2 \%$ proof stress of $868 \mathrm{MPa}$, the peak compressive value of residual stress was observed to decay with a log-linear trend over all 10,000 fatigue cycles applied to the blade - see Figure 6). The FE modelling of residual stresses in the fir-tree region presented in this paper is able to predict this decay in their value under fatigue loading. Kodama [10] also observed a log-linear trend for the decay of shot peening-induced surface residual stress in carbon steel under fatigue loading subsequent to the first load 
cycle, in other words the magnitude of the surface residual stress was linearly proportional to the logarithm of the number of applied fatigue cycles, as also found in the present work.

\section{FE Modelling}

A finite element model was developed to simulate the residual stress profile that develops on the fir-tree after shot peening and these results were cross-correlated with the measured values. The model was then further refined to determine the effect of centrifugal service loading on the residual stress profile. Initial work in this area considered the various finite element modelling methodologies and, considering the superposition requirement for the centrifugal loading, it was decided to use quench loading simulation in the model in order to generate an appropriate residual stress profile. 2D plane strain models were created in ANSYS v12 for both the flat samples and the fir-tree geometry assuming an elastic-perfectly plastic material constitutive response. Models were constructed using two 8-noded element types, PLANE77 and PLANE183. The PLANE77 element is a thermal solid element applicable to 2D steady state or transient thermal analysis. For structural analysis this element is replaced by the PLANE183 which has a quadratic behaviour and is well suited to creating irregular meshes to analyse plasticity and large strain loading. Additional material properties used in the FE work were specific heat $460 \mathrm{~J} / \mathrm{kgK}$, thermal coefficient of expansion $1.16 \times 10^{-5}$ and thermal conductivity $0.1 \mathrm{~W} / \mathrm{m}^{2 \circ} \mathrm{C}$.

The FE modelling process therefore had two parts, the first one using a transient thermal analysis to create a temperature profile for simulation of quenching, which generated the residual stress field; while the second part was a structural analysis to model the effect of applied service loads on that residual stress field. The model takes no account of any influences of microstructure or surface roughness on fatigue life, and the mesh configuration is shown in Figure 7. The modelling process was initially applied to flat sample geometry to check the correlation between predicted residual stress from the FE model and experimentally measured synchrotron data. The quenching simulation of shot peened 
residual stresses was then applied to the fir-tree geometry. Table 3 illustrates the steps in the modelling process.

As an indication of the effectiveness of this approach in predicting the residual stress resulting from the shot peening process, the residual stress profile obtained from the FE analysis of the flat sample geometry is shown in Figure 8, superimposed on measured SXRD data obtained from shot peened flat blade specimens with $200 \%$ coverage. There is a good correlation between the measured data and the output from the FE model, with a regression analysis yielding a value for $R^{2}$ of 0.978 . SXRD data is provided for two samples shot peened with $200 \%$ coverage (S10 and S11) and, although there is a separation between the experimental and model residual stress curves over the range of depths between $0.1 \mathrm{~mm}$ and $0.2 \mathrm{~mm}$ in the specimens, the data show a good correlation in the magnitudes of the peak compressive and tensile stresses, as well as in the depth below the surface where the peak compressive stress is attained. Figure 8 also shows SXRD residual stress data measured on an as-peened fir-tree first serration with $200 \%$ coverage. The residual stress values near the surface are close to those observed with the flat plate samples, although the depth into the blade over which high compressive residual stress values are maintained is significantly greater at the fir-tree serration than found with the flat plate samples. This is believed to be related to the plastic constraint present at the fir-tree serration. Nonetheless, the close correlation between residual stress values in the region of interest for fatigue crack growth gives confidence that the approach that has been adopted in this paper is useful for fatigue life prediction of steam turbine blades.

\section{Effect of Service Loading}

The quench loading simulation of the shot peening process, followed by an elastic/perfectly plastic structural analysis gives a good approximation of the residual stress distribution obtained from SXRD measurements and can be applied to either flat specimens or to the blade fir-tree root region to determine the effect of centrifugal service loading on the residual 
stress profile in a last stage turbine blade. The output net residual stress levels can be related back to input material and shot peening parameters and hence used to assess the likely fatigue performance of a blade. The technique is illustrated in Figure 9 for the flat specimens, which depicts the resultant residual stress field during operation at a turbine speed of $3,000 \mathrm{rpm}$, which is obtained from the superposition of the as-peened residual stress and the applied centrifugal stress at 3,000 rpm.

For the case of interest in this work, i.e. the first serration on the fir-tree of the last stage blade, centrifugal loading was applied to the FE model in three steps, and the effect on the residual stress profile evaluated progressively. The first step was to apply a stress corresponding to the normal operating speed of $3,000 \mathrm{rpm}$. The second step was to simulate a $10 \%$ overspeed $(3,300 \mathrm{rpm})$ normally experienced during balancing of the rotor after reblading. The third step simulated the worst case of the turbine spinning at 3,600 rpm, which could be experienced during statutory in-situ testing of the overspeed protection systems. The centrifugal stress increases by $21 \%$ at $3300 \mathrm{rpm}$, and $44 \%$ at $3600 \mathrm{rpm}$ and this leads to localised yielding on the surface of the first fir-tree serration.

Figure 10 shows the effect of applying increasing centrifugal loads corresponding to the turbine spinning at $3,000,3,300$ and $3,600 \mathrm{rpm}$. The first cycle of loading at $3,000 \mathrm{rpm}$ reduces the surface compressive residual stress from $-850 \mathrm{MPa}$ to $-766 \mathrm{MPa}$, while after loading at $3,300 \mathrm{rpm}$ it reduces to $-734 \mathrm{MPa}$ and after loading at 3,600 rpm it reduces to -690 $\mathrm{MPa}$. This reduction in the compressive peak stress is controlled by the constraint of the firtree serration geometry, so that even though the applied centrifugal stress corresponding to rotation at 3,300 rpm and $3,600 \mathrm{rpm}$ were above yield at the surface, the reduction of residual stress at the surface was small. These results agree with the conclusion of Soady et al [11] that cyclic plastic deformation of a notched shot peened specimen (intended to simulate the blade connection geometry) under 3-point bending resulted in the retention of near-surface compressive residual stresses from shot peening in the direction of loading, and 
approximately a $20 \%$ reduction in the orthogonal residual stress after one cycle of loading with a minor subsequent change in residual stress value up to $50 \%$ of the fatigue life of the specimens. The magnitude of surface stress obtained from the FE model is more compressive than found in the measured SXRD data from flat or fir-tree specimens which is shown in Figure 8 . This is likely to be caused by the elastic-perfectly plastic assumption used in the FE model; however the effect of applied loading cycles on residual stress values is believed to be valid and relevant to blade operation. FE model refinement could replace the EPP assumption with, for example, a kinematic hardening model. It is also worth noting that the measured SRXD data for the first fir-tree serration was further supported through surface laboratory residual stress measurements made using a Proto iXRD instrument on two used service blades. Figure 11 shows one such blade in the measurement position on the instrument. The residual stress was measured in the centre of the top serration along the direction of the groove with a goniometer range of $\pm 30^{\circ}$ and transverse to the groove, i.e. in the longitudinal direction of the blade, with a goniometer range of $\pm 12^{\circ}$. The results of these measurements are given in Table 4 below and show that the ex-service blade that experienced normal operating conditions has a closely equi-biaxial surface stress of approximately $554 \mathrm{MPa}$, which is similar to the SXRD values shown in Figure 8. However, the blade from the failed $600 \mathrm{MW}$ unit has a much lower residual stress that is also no longer equi-biaxial, presumably reflecting the overload experienced during failure of the steam turbine.

Figure 12 compares residual stress curves obtained from FE modelling under centrifugal loading equivalent to normal turbine operation at a speed of 3,000 rpm for a blade which has experienced three prior loading histories:

- Shot peened condition running at 3,000 rpm with no previous overspeed cycle

- Shot peened condition running at 3,000 rpm after a single previous overspeed cycle at 3,600 rpm 
- Un-peened condition running at 3,000 rpm after a previous overspeed cycle at 3,600 rpm

It is clear from these results that there is a significant service advantage in residual stress terms and hence blade performance under fatigue or stress corrosion cracking conditions, that results from shot peening the fir-tree root, as the surface stress during normal operation after the application of an overspeed cycle is predicted to be $25 \mathrm{MPa}$ as opposed to $675 \mathrm{MPa}$ for the unpeened condition.

\section{Conclusions}

An elastic-perfectly plastic (EPP) FE model has been developed that uses thermal quenching to simulate the residual stress profile obtained via shot peening. It has given a good agreement with the measured stress profile on shot peened blades for flat specimens, see Figure 8. Application of the service centrifugal loading to the fir-tree serration of a turbine blade provides the data illustrated in Figure 10 and Figure 12.

The benefit of the shot peening process to the fir-tree serration stresses can clearly be seen in Figure 12, where centrifugal loading corresponding with $3,000 \mathrm{rpm}$ is applied after the application of overspeed cycles. The shot peened condition has a predicted surface stress of $25 \mathrm{MPa}$ as opposed to the value of $675 \mathrm{MPa}$ obtained with the un-peened condition. A shot peened blade is therefore much better able to resist the initiation of fatigue or stress corrosion cracks during service due to the residual stresses enhancing the integrity of the turbine blades. Surface residual stress measurements on two ex-service blades have confirmed the predictions from the model.

The results of the FE modelling correlate well with work by Soady et at [11] showing that a notched specimen does not lose all of its compressive stress when localised yielding takes place and that shot peening is beneficial for steam turbine blades in low cycle fatigue 
applications. This would be true even in the extreme case of centrifugal loading on a fir-tree root due to a $3,600 \mathrm{rpm}$ overspeed condition (normally $3,300 \mathrm{rpm}$ would be the maximum).

\section{Acknowledgments}

The authors acknowledge support from the ESRF in Grenoble, for the allocation of beam time together with assistance from beamline scientists Drs T Buslaps, A Steuwer and A Evans during experiments MA-326 and ME-1165. Funding support from the Eskom research program is also gratefully acknowledged, and assistance from $R$ Scheepers with the finite element modelling.

\section{References}

1. Jonas, O. and Machemer, L. (2008), Steam turbine corrosion and deposits problems and solutions, Proceedings of the $37^{\text {th }}$ Turbomachinery Symposium, Houston, TX, 811 September 2008, pp.211-228.

2. Nel, W. (2004), Duvha power station - blade analysis, Eskom Technical Report, MT320/2005.

3. James, M.N., Newby, M., Hattingh, D.G., Steuwer, A. (2010), Shot peening of steam turbine blades: residual stresses and their modification by fatigue cycling, Procedia Engineering 2, pp.441 - 450.

4. Johannes, M. (2004), Turbine blade root inspections - an assessment and feasibility study of UT capabilities, Eskom Research Report RES/RR/03/22773.

5. Pollak, H., Pfitzinger, E., Thamm, N., Schwarz, M. (2004), Design And materials for modern steam turbines with two cylinder design up to 700 MW, Siemens AG, Power Generation, Germany.

6. McCloskey, T., Dooley, R., McNaughton, W. (1999), Turbine steam path damage: theory and practice Volume $1,7^{\text {th }}$ edition, Electric Power Research Institute, Palo Alto, CA. 
7. McCloskey, T., Dooley, R., McNaughton, W. (1999), Turbine steam path damage: theory and practice Volume 2, $5^{\text {th }}$ edition, Electric Power Research Institute, Palo Alto, CA.

8. Botha, J.P. (2005), Shot peening process for stage 5 turbine blades, South African Airways Technical Procedure for Eskom.

9. Prevéy, P.S. and Cammett, J.T. (2002), The effect of shot peening coverage on residual stress, cold work and fatigue in Ni-CR-Mo low alloy steel, Proceedings of the $8^{\text {th }}$ International Conference on Shot Peening, Garmisch-Partenkirchen, Germany, 16-20 September 2002.

10. Kodama, S. (1972), The behaviour of residual stress during fatigue stress cycles, Proceeding of the $1^{\text {st }}$ International Conference on Mechanical Behaviour of Metals, (ICM1), Society of Material Science press, Kyoto, pp. 111-118.

11. Soady, K., Mellor, B., Shackleton, J., Morris, A., Reed, P. (2011), The effect of shot peening on notched low cycle fatigue, Materials Science and Engineering $\mathbf{A}(\mathbf{5 2 8})$, pp.8579-8588. 
Table 1 Shot peened condition and stress ranges used in SXRD experiment MA-326.

\begin{tabular}{|c|c|c|c|c|c|c|}
\hline Specimen & Coverage & \multicolumn{5}{|c|}{$\begin{array}{c}\text { SXRD MA-326 Applied Stress } \\
\text { MPa }\end{array}$} \\
\hline 1 & $75 \%$ & As-peened & 868 & 910 & & \\
\hline 2 & $75 \%$ & As-peened & & & 600 & $\begin{array}{c}868 \pm 20 \\
10,000 \text { cycles }\end{array}$ \\
\hline 3 & $75 \%$ & \multicolumn{5}{|c|}{ Used as test piece in Instron, no diffraction measurements } \\
\hline 4 & $100 \%$ & As-peened & 868 & 910 & & \\
\hline 5 & $100 \%$ & As-peened & & & 600 & $\begin{array}{c}868 \pm 20 \\
10,000 \text { cycles }\end{array}$ \\
\hline 6 & $100 \%$ & \multicolumn{5}{|c|}{ Not tested } \\
\hline 7 & $150 \%$ & As-peened & 868 & 910 & & \\
\hline 8 & $150 \%$ & As-peened & & & 600 & $\begin{array}{c}868 \pm 20 \\
10,000 \text { cycles }\end{array}$ \\
\hline 9 & $150 \%$ & \multicolumn{5}{|c|}{ Not tested } \\
\hline 10 & $200 \%$ & As-peened & 868 & 910 & & \\
\hline 11 & $200 \%$ & As-peened & & & 600 & $\begin{array}{c}868 \pm 20 \\
10,000 \text { cycles }\end{array}$ \\
\hline 12 & $200 \%$ & \multicolumn{5}{|c|}{ Not tested } \\
\hline
\end{tabular}

Table 2 Shot peened condition and stress ranges used in SXRD experiment ME-1165.

\begin{tabular}{|c|c|c|}
\hline Specimen & Coverage & $\begin{array}{c}\text { SXRD ME1165 Applied Stress } \\
\text { MPa }\end{array}$ \\
\hline \multirow{10}{*}{6} & \multirow{10}{*}{$100 \%$} & First scan - As peened \\
\hline & & Second scan - 620 \\
\hline & & Third scan - 10 cycles $600 \pm 20$ \\
\hline & & Fourth scan - 100 cycles $600 \pm 20$ \\
\hline & & Fifth scan $-1,000$ cycles $600 \pm 20$ \\
\hline & & Sixth scan $-10,000$ cycles $600 \pm 20$ \\
\hline & & Seventh scan - 100,000 cycles $600 \pm 20$ \\
\hline & & Eighth scan - 868 \\
\hline & & Ninth scan - 100 cycles $848 \pm 20$ \\
\hline & & Tenth scan $-10,000$ cycles $848 \pm 20$ \\
\hline
\end{tabular}

Fatigue and Fracture of Engineering Materials and Structures 
Table $3 \quad$ Steps in the FE modelling process.

\begin{tabular}{|c|c|}
\hline STEP & PROCESS \\
\hline \multicolumn{2}{|c|}{$\begin{array}{l}\text { Steps } 1-3 \text { were run as a transient thermal analysis to obtain a temperature } \\
\text { distribution from the surface of the model }\end{array}$} \\
\hline 1 & Apply uniform temperature on all the elements of $500^{\circ} \mathrm{C}$ \\
\hline 2 & $\begin{array}{l}\text { Apply convection to the surface elements with a coefficient }= \\
110,000 \mathrm{~W} / \mathrm{m}^{20} \mathrm{C} \text { and bulk temperature of }-1300^{\circ} \mathrm{C} \text { for a period of } \\
0.4 \mathrm{~s}\end{array}$ \\
\hline 3 & $\begin{array}{l}\text { Apply convection to surfaces with coefficient }=3,500 \mathrm{~W} / \mathrm{m}^{2 \circ} \mathrm{C} \text { and } \\
\text { bulk temp } 0^{\circ} \mathrm{C} \text { for a period of } 0.1 \mathrm{~s}\end{array}$ \\
\hline \multicolumn{2}{|r|}{ The following steps were run as steady state structural analysis } \\
\hline 4 & $\begin{array}{l}\text { Apply temperature distribution as calculated in Step } 3 . \text { This } \\
\text { results in tensile yielding on surface }\end{array}$ \\
\hline 5 & $\begin{array}{l}\text { Apply uniform temperature of } 500^{\circ} \mathrm{C} \text { to return to the original state } \\
\text { in Step 1. This results in a compressive surface residual stress }\end{array}$ \\
\hline \multicolumn{2}{|c|}{$\begin{array}{l}\text { After generating the residual stress profile, apply centrifugal loads to the fir- } \\
\text { tree model and report superimposed residual stress profiles }\end{array}$} \\
\hline 7 & $3000 \mathrm{rpm}$ \\
\hline 8 & $\sqrt{2}=$ \\
\hline 9 & $3300 \mathrm{rpm}$ \\
\hline 10 & $0 \mathrm{rpm}$ \\
\hline 11 & $3600 \mathrm{rpm}$ \\
\hline 12 & $0 \mathrm{rpm}$ \\
\hline
\end{tabular}

Table 4 Residual stress measured in top serration of used blades using the Proto iXRD instrument.

\begin{tabular}{ccc}
\hline & Residual Stress (MPa) & Residual Stress (MPa) \\
& Along groove & Transverse \\
\hline Ex-service blade from 2003 incident & $-387.6 \pm 17.2$ & $-480.4 \pm 26.2$ \\
Ex-service blade - normal operation & $-554.3 \pm 11.3$ & $-532.8 \pm 27.8$ \\
\hline
\end{tabular}


Figure 1 Steam path schematic (indicated by the green arrows)
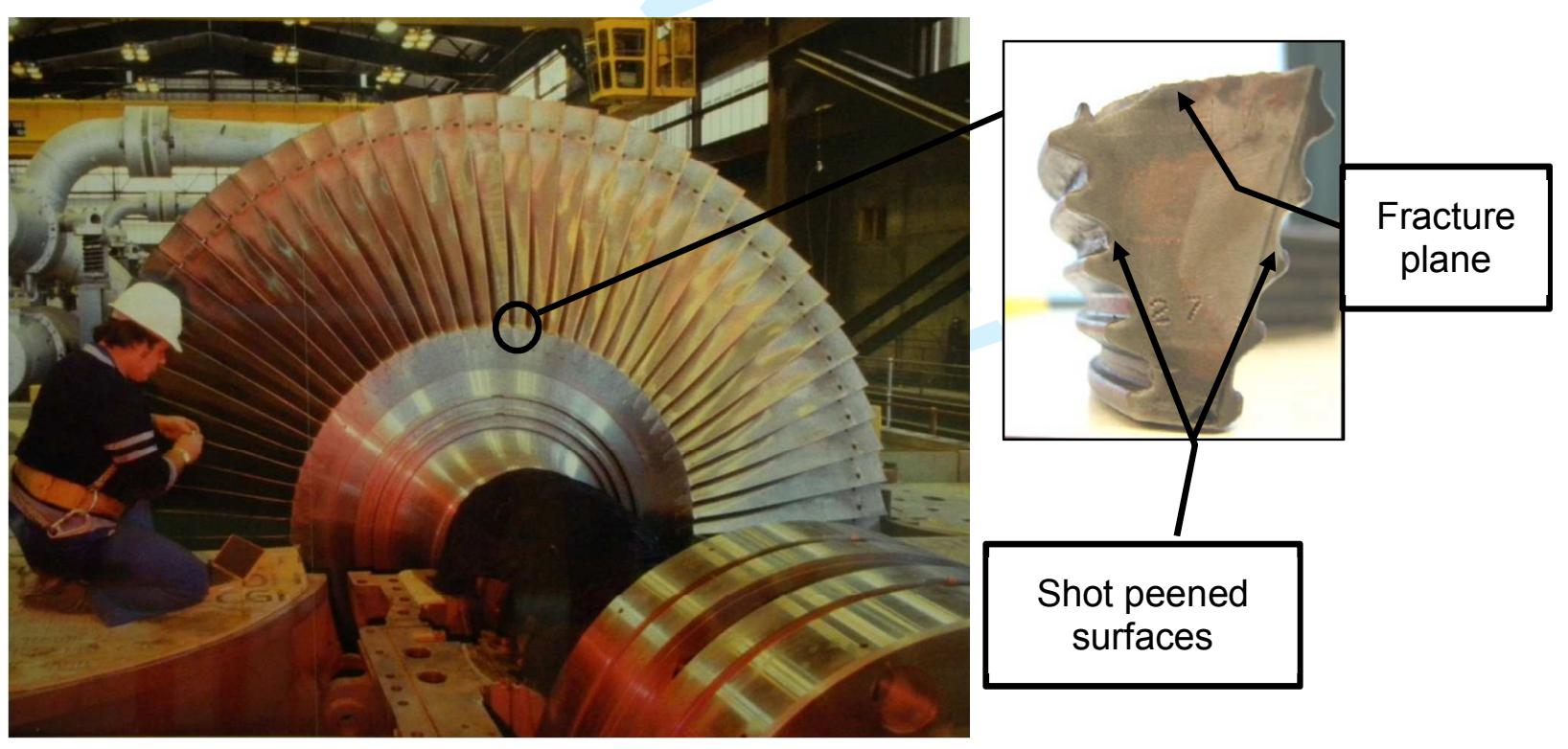

Figure 2 Axial View of a Low Pressure rotor from a $600 \mathrm{MW}$ turbo-generator showing the last stage blades of the turbine, with an inset image of the failed fir-tree root. 
Figure 3 Turbine blade mode shapes. 

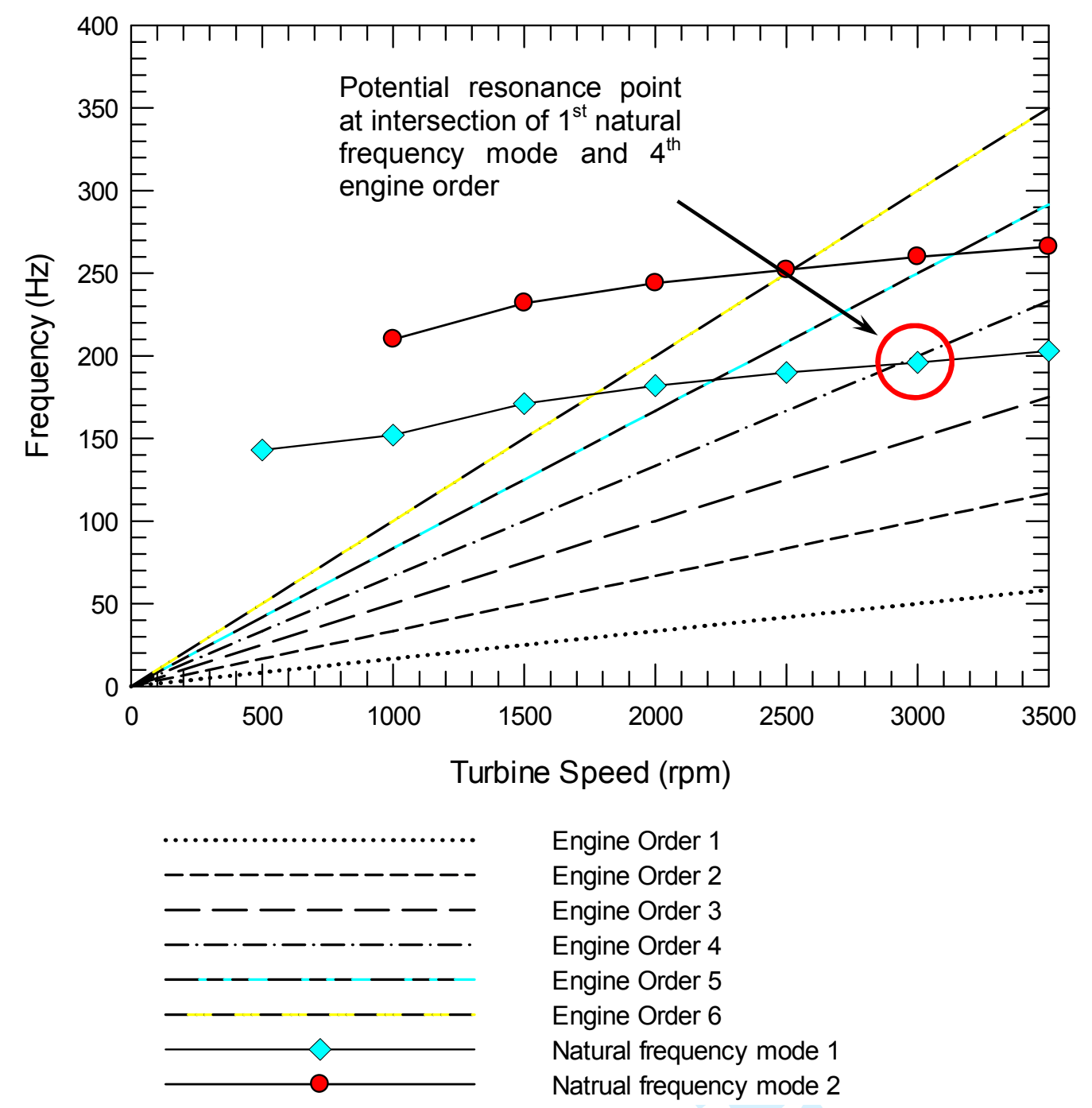

Figure 4 Typical Campbell diagram showing the first six engine order lines and the potential for resonance of the first disk mode with the fourth engine order. 


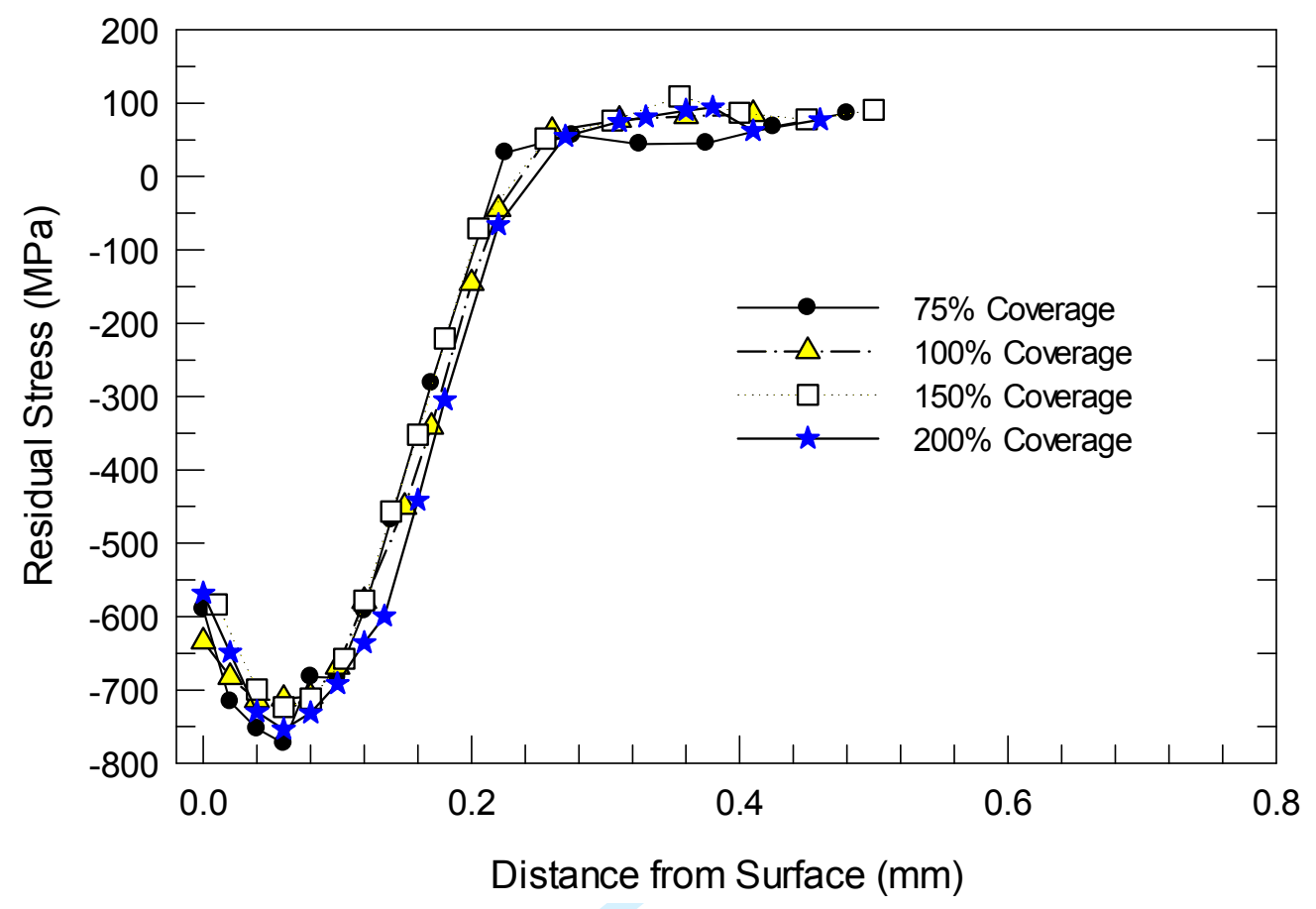

Figure 5 SXRD residual stress measurements over the first $0.8 \mathrm{~mm}$ below the specimen surface for the as-peened condition.

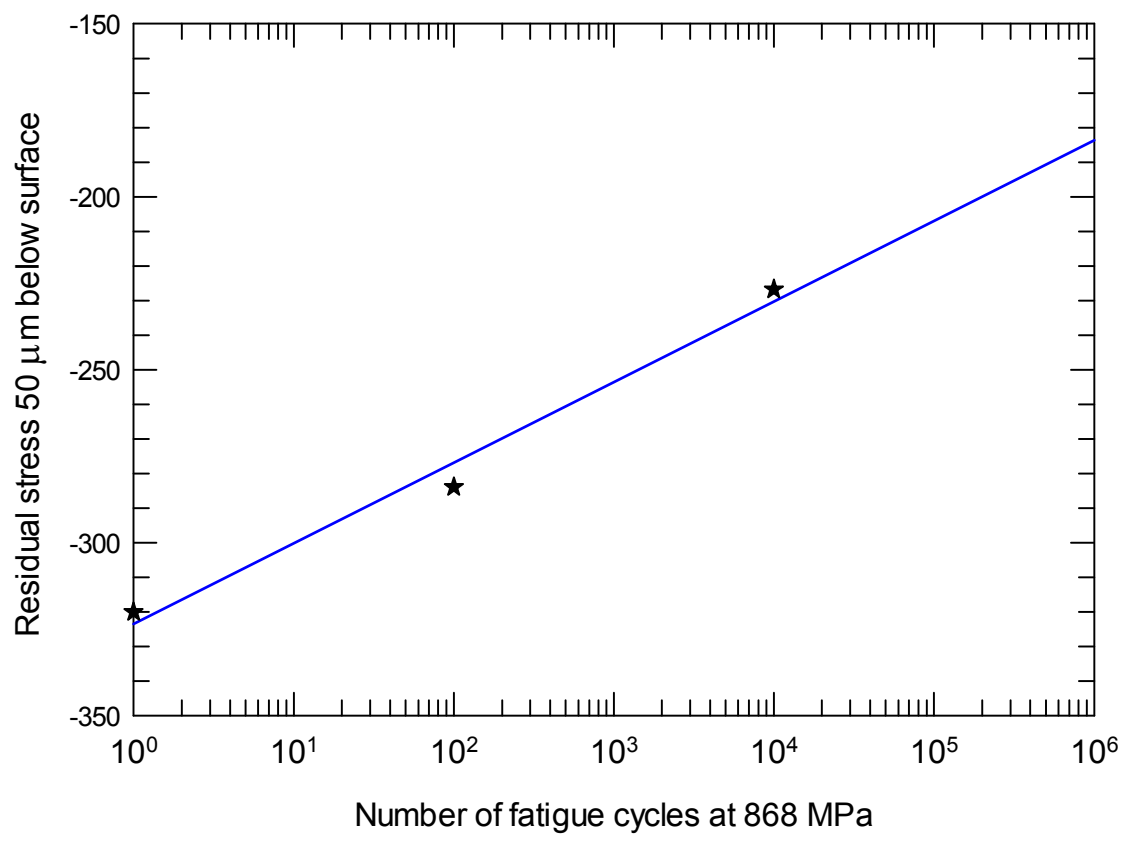

Figure 6 Log-linear decay observed in residual stress $50 \mu \mathrm{m}$ below the surface of a shot peened specimen with the application of fatigue cycles (mean stress 848 $\mathrm{MPa}$ and amplitude of $\pm 20 \mathrm{MPa}$ ). 
Figure 7 Mesh of turbine blade fir-tree root. The inset shows the detail around the top serration.

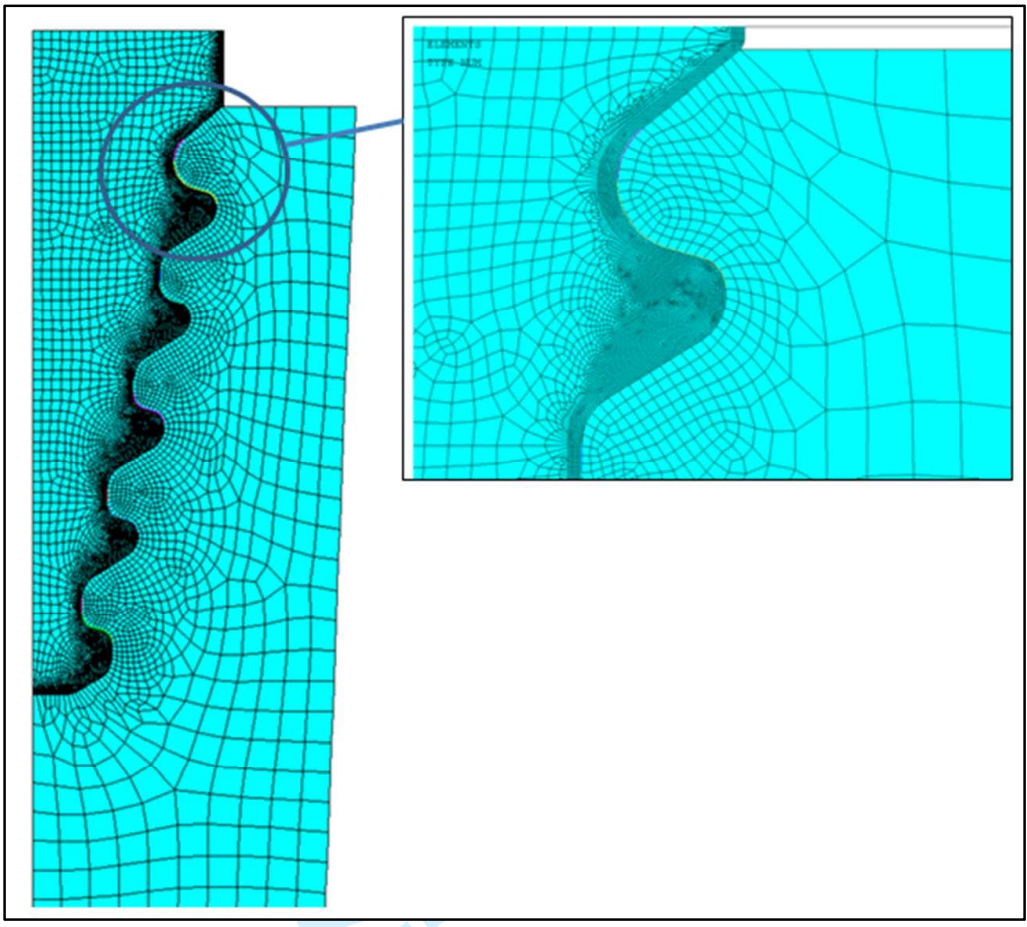


Figure 8 Comparison between the finite element and synchrotron diffraction residual stress data for the as-peened flat samples at $200 \%$ coverage. The measured SXRD data from the fir-tree root is also shown for comparison. 


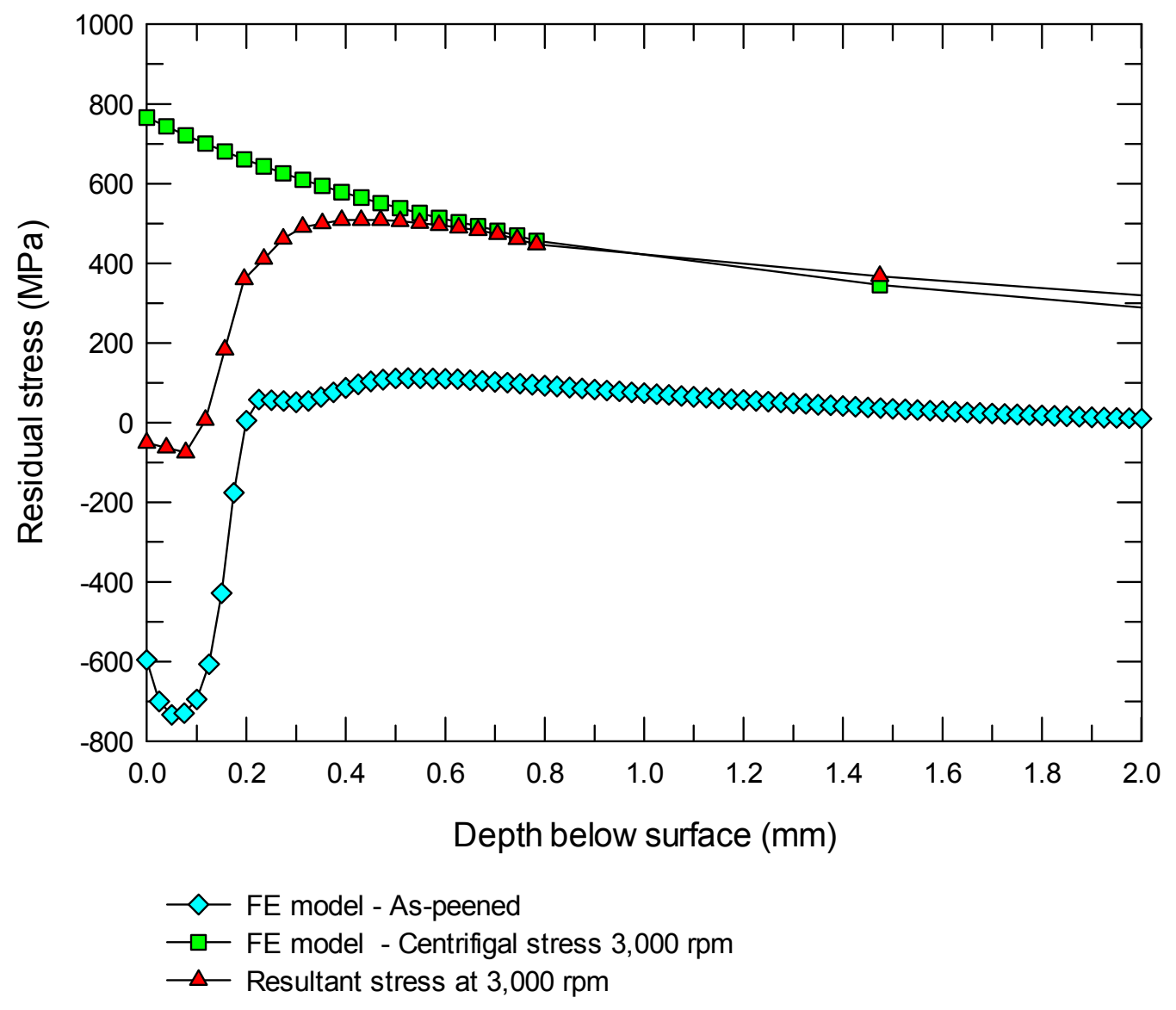

Figure 9 FE model results showing the net residual stress in the flat specimens resulting from the combination of shot peening and centrifugal loading equivalent to a turbine speed of $3,000 \mathrm{rpm}$.

Fatigue and Fracture of Engineering Materials and Structures 


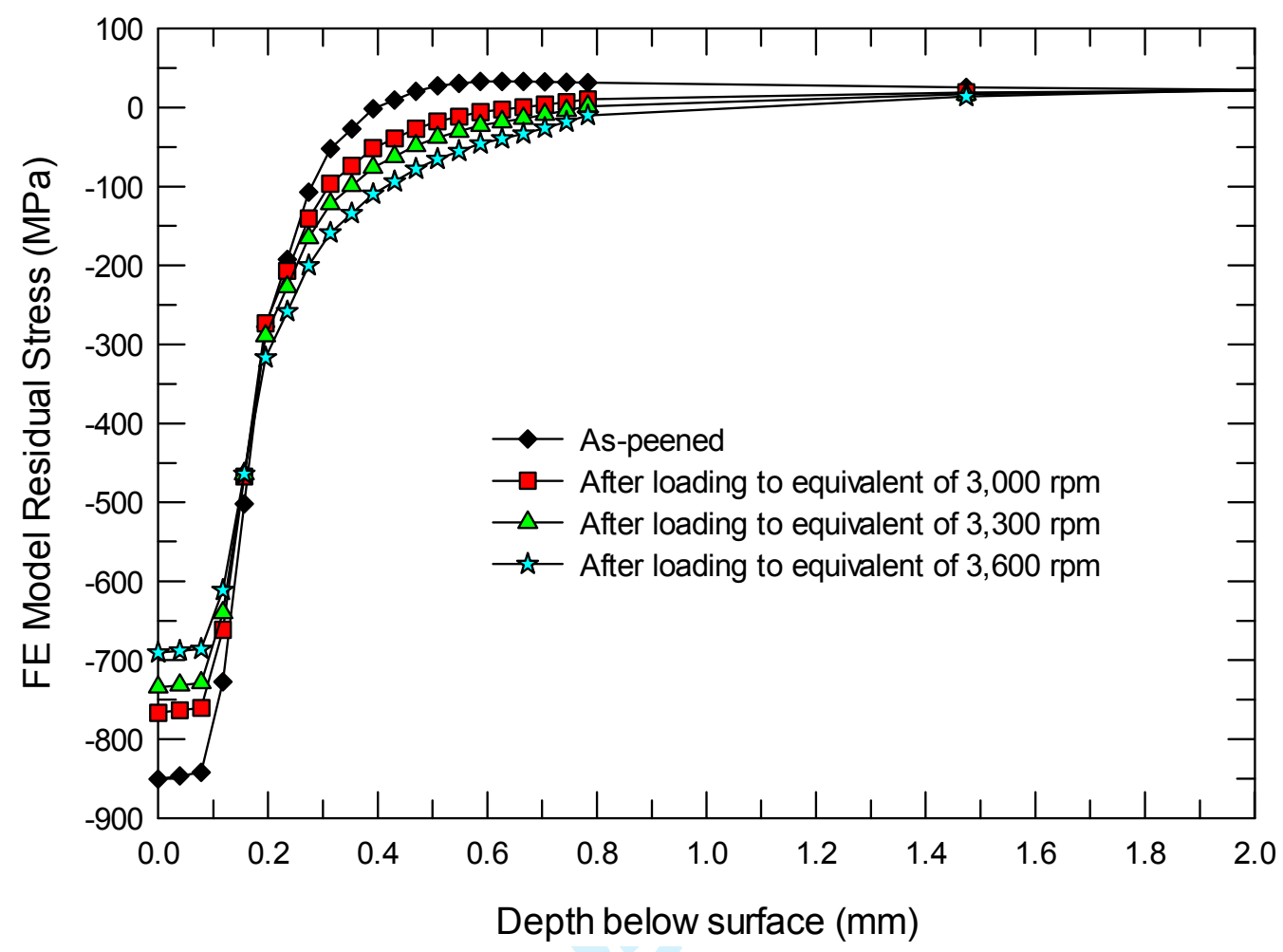

Figure 10 Comparison of residual stress profiles on the first serration of the fir-tree with a stationary turbine (as-peened) and after the application of centrifugal loading equivalent to three different turbine speeds. 


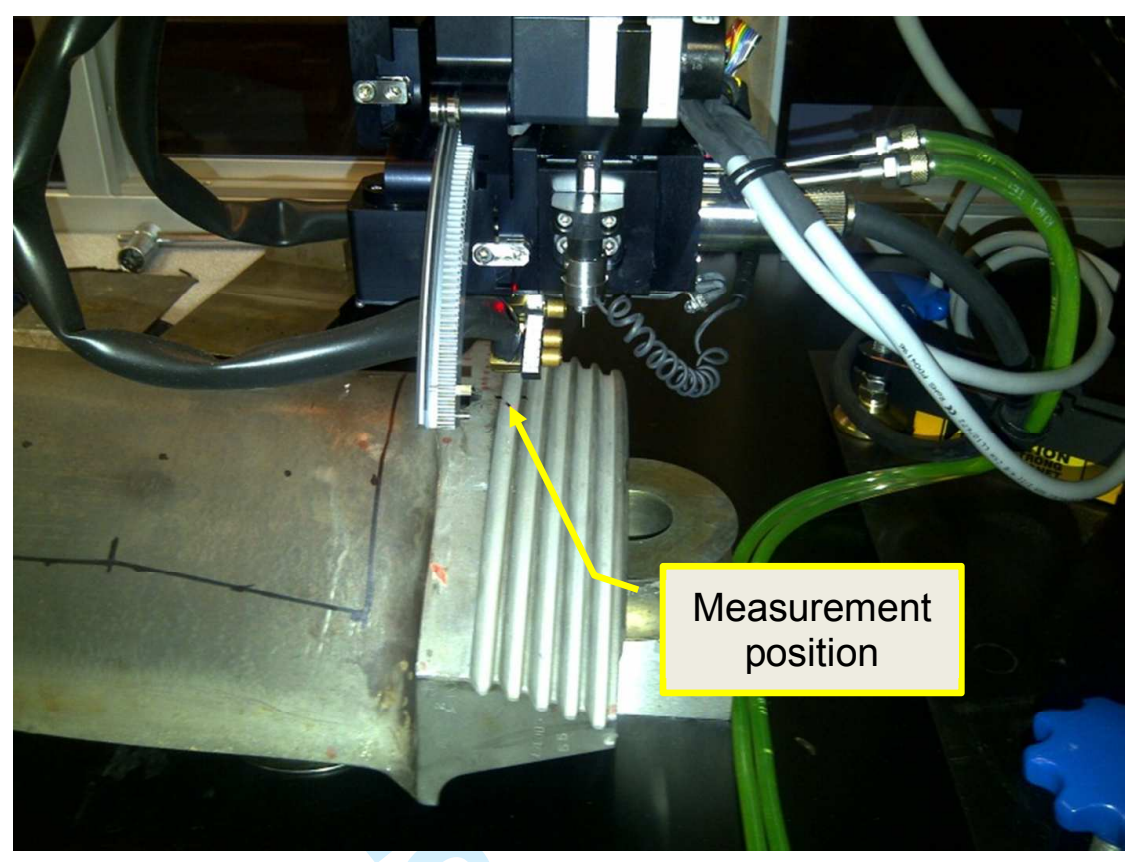

Figure 11 Ex-service blade in position for residual stress measurement on the Proto iXRD instrument. 


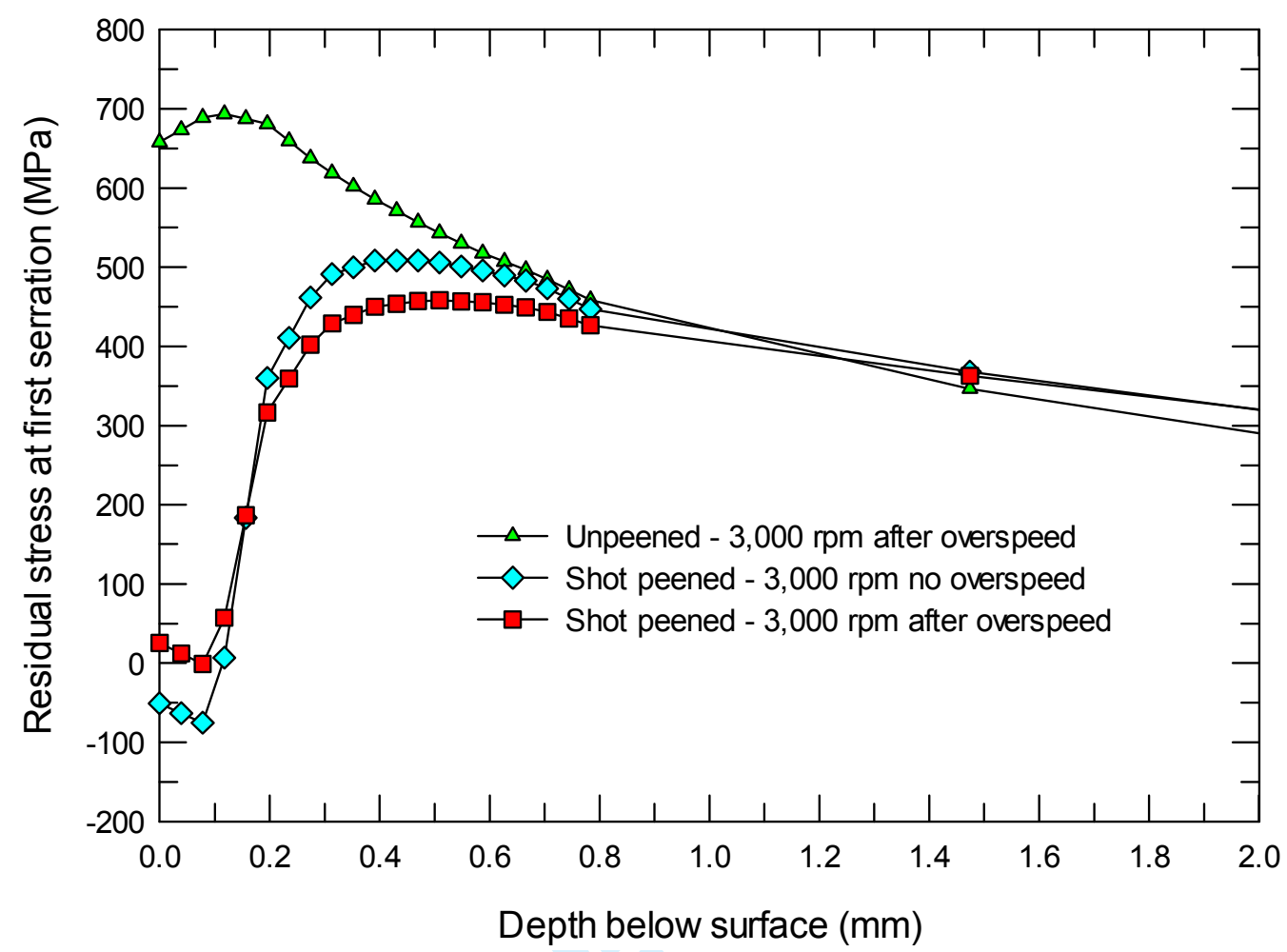

Figure 12 Comparison of stress profiles on the fir-tree first serration at 3,000rpm. 